\title{
Two-phase fed-batch modification for 48 hour peak expression of hepatitis B surface antigen in Pichia pastoris shake flask system
}

\begin{abstract}
A study of the Mut+ phenotype for the expression of recombinant hepatitis B surface antigen (HBsAg) in Pichia pastoris strain GS115 using the pPIC3.5K vector with a two-phase fedbatch protocol in a shake flask system is described. Expression levels of HBsAg protein of $6.74 \mathrm{~g} \mathrm{Lī} 1$ Dry Cell Weight (DCW) and $26.07 \mathrm{mg} \mathrm{Lī} 1$ of HBsAg concentration were achieved $48 \mathrm{~h}$ from the induction point which added to a $120 \mathrm{~h}$ reduction in production period in comparison with MutS expression (168 h). The use of the pPIC3.5K-HBsAg plasmid in the Mut+ phenotype enhanced the expression of HBsAg by a nearly 13 times higher volumetric productivity in the first $24 \mathrm{~h}$ and 35 times higher at peak production concentration. Comparison of AOX expression cassettes relative to the HBsAg gene in the role of mRNA secondary structure during translation initiation revealed that HBsAg possesses lower folding stability with AOX1 Mut+ phenotype. The results from this study demonstrated that expression of HBsAg with Mut+ AOX1 promoter is adequate as an alternative for the production of HBsAg. In addition, the AOX promoter of the Mut+ phenotype was observed to be better suited for HBsAg expression, which correlates with the ease of translation initiation under shake flask conditions.
\end{abstract}

Keyword: Hepatitis B surface antigen; Genetic cloning; Protein expression; Pichia pastoris; Recombinant protein; mRNA secondary structure 